Environment Conservation Journal 14(1\&2) 51-54, 2013

ISSN 0972-3099 (Print) 2278-5124 (Online)

Abstracted and Indexed

\title{
Comparative evaluation of various extraction techniques for analysis of Hexaconazole residues in Soils
}

\author{
Khushbu Sharma ${ }^{1}$, P. E. Joseph ${ }^{1}$, Jashbir Singh ${ }^{2}$, Rishi Kumar Shukla $\varpi^{2}$
}

Received:17.01.2013

Revised:21.02.2013

Accepted: 26.03.2013

\begin{abstract}
The extraction of hexaconazole (fungicide) residues from the soil samples was conducted by noval extraction techniques like ASE along with traditional methods like soxhlet, column and mechanical shaking. The samples have been collected from different agro-climatic zones of Uttar Pradesh region. The analysis was performed without clean-up by HPLC. The results showed that the ASE and HPLC techniques are clearly faster, more sensitive and more cost effective than conventional methods. The recovery efficiency of ASE was above $90 \%$ in all studies.
\end{abstract}

Keywords: soil, hexaconazole, HPLC, cost effective

\section{Introduction}

Hexaconazole [(RS)-2-(2,4-dichlorophenyl)- 1-(1H1,2,4-triazol- 1-yl)hexan-2-ol] represents one example of modern and effective fungicide (Figure 1 ), among the active ingredients used in the treatment of sicilian vines to study photodegradation mechanisms, in consequence of high levels of residues found by researchers (Santoro et al. 2000). It has broad spectrum action against ascomycetes and basidiomycetes (Worthington, 1991) is highly efficacious to control staining and interferes with fungal sterol synthesis fundamentals for controlling plant fungal pathogens (Santoro et al. 2000). Singh and Dureja, (2000) found that its toxicity to human, mammals, fish and bird by oral, inhalation or contact route is low to moderate.

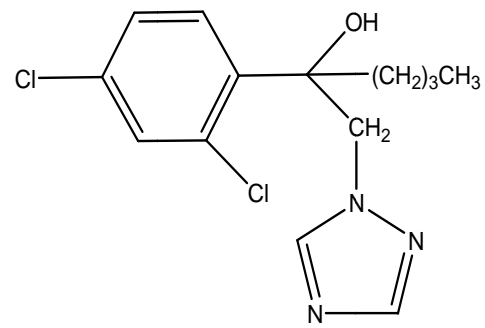

Figure. 1

\footnotetext{
Author's Address

${ }^{1}$ Department of Chemistry, St. John's College, Agra

${ }^{2}$ Department of Chemistry, Gurukul Kangri Vishwavidhalaya, Hardwar E-mail: khushbu.k.sharma@gmail.com
}

Based on statistical data for 19 countries, the WHO estimated that worldwide there have been as many as 50,000 cases annually of pesticide poisoning. The mortality rate has been $1 \%$ in countries where medical treatment is readily available, so deaths are estimated to be about 5000 a year. However, it is reckoned that the real number of poisonings is considerably greater at about 2 million. About 40,000 persons die and admittedly $70 \%$ of the lethal cases occur in developing countries. This shows that every $17 \mathrm{~min}$ a person dies due to pesticide poisoning and every $10 \mathrm{~min}, 28$ subjects are poisoned by pesticide (Roy et al., 1995; Ekstrom et al., 1996; Neidert and Saschenbrecker, 1996). Insecticides, fungicides, acaricides and herbicides have been excessively used in agriculture which put the health of the consumers at risk with adverse effects (Blanco et al., 2002a, b; Ripley et al., 2003; FDA, 1993). It is quite apparent that such state of affairs calls for the need of more accurate, costeffective and rapid analytical techniques capable of detecting the minimum concentrations of pesticide residues (EL-Saeid and Shaht, 2000; Valenzuela et al., 2000; Okihashi et al., 2005). Simple, rapid and less labor intensive extractions techniques are required to minimize the use of toxic solvents. Different noval instrumental extraction techniques have been developed in recent years. Advance extraction techniques, ASE and SFC are widely used in pesticide residue field. ASE (accelerated 
solvent extraction) also called pressurized solvent extraction, has been used since 1995. ASE is an extraction under elevated pressure and temperature. It represents an exceptionally effective extraction technique with the advantages of shorter extraction times and lower consumption of solvents. It allows the universal use of solvents or solvent mixtures with different polarities and individually variable pressures of 5-200 atm in order to maintain the extraction solvent in a liquid state and temperatures ranging from room temperature up to $200^{\circ} \mathrm{C}$ in order to accelerate extraction. The solvent volume can be reduced because the solubility increases (Hubert et al. 2000).The present study deals with the comparative evaluation of different extraction techniques ASE, soxhlet, column and mechanical shaking for the extraction of hexaconazole residues in soils of Uttar Pradesh, India.

\section{Material and Methods Samples Collection and Preparation}

The soil samples were collected from cultivated fields at $0-15 \mathrm{~cm}$ depth with no background of fungicide application and varying properties representing different agro-climatic zones of Uttar Pradesh, India. (i) Alluvial soil from Agra (ii) Laterite soil from Deoria (iii) Red soil from Mirzapur and (iv) Black soil from Pilibhit. The soil samples were air dried under shade, ground and passed through a $2 \mathrm{~mm}$ mesh sieve. The sieved soils were stored in polythene bags for further experiments.

\section{Recovery Assays}

Untreated samples of the four soil types were spiked with hexaconazole at 0.1 and $0.2 \mu \mathrm{g} \mathrm{g}^{-1}$ levels. The spiked samples were allowed to equilibrate for one hour prior to extraction. Three replicates were analyzed to calculate the recovery.

\section{Pesticide Standard}

Stock solution of $1000 \mu \mathrm{g} \mathrm{mL} \mathrm{m}^{-1}$ was prepared by dissolving $25 \mathrm{mg}$ of hexaconazole in $25 \mathrm{ml}$ of acetone for spiking, recovery and residue analysis.

\section{HPLC}

The residues were dissolved in HPLC grade methanol and estimated on Waters ${ }^{\circledR}$ HPLC equipped with 515 HPLC Pump and 2487 dual lambda absorbance UV-Detector. A Spherisorb C18 column (4.6 x $250 \mathrm{~mm}), 5 \mu \mathrm{m}$ was used for chromatographic analysis. Mobile phase comprised of isocratic mixer of methanol: water (80:20) with the flow rate of $0.8 \mathrm{~mL} \mathrm{~min}^{-1}$. Chromatograms were acquired at $212 \mathrm{~nm}$. Injection volume used was 20 $\mu \mathrm{L}$.

\section{Extractions Procedures}

\section{Fortification}

Ten grams of soil was taken in $100 \mathrm{~mL}$ beakers in triplicate. In first set, $1.0 \mu \mathrm{g}$ hexaconazole was added to get $0.1 \mu^{-1}$ and in another set, soil was treated with $2.0 \mu \mathrm{g}$ to get $0.2 \mu \mathrm{g} \mathrm{g}^{-1}$ level of fortification. Soil was mixed thoroughly with glass rod and acetone was added to completely dip the soil. After complete evaporation of solvent, soil was again mixed to get uniform distribution of residues. The following procedures were tried to evaluate the extraction efficiency.

\section{Mechanical Shaking Method}

Fortified soil (10 g) was taken in a beaker and 20 $\mathrm{mL}$ of acetone was added. It was then shaken intermittently for 20 minutes a mechanical shaker. The supernatant was transferred and filtered using Whatman No. 1 filter paper. The extraction process was repeated two more time with the addition of fresh solvent. The extracts were pooled, concentrated to dryness, diluted with $20 \mathrm{ml}$ saturated $\mathrm{NaCl}$ solution and partitioned with dichloromethane ( 3 X 25). Dichloromethane phase concentrated to dryness and no further cleanup was carried out. Residues were dissolved in HPLC grade methanol for analysis.

\section{Soxhlet Extraction}

Fortified sample (10 g) was packed in filter paper thimble and placed in a thimble holder. The soxhlet extraction apparatus was assembled and fresh acetone was added. The extraction was carried out for four hours. The extract thus obtained was concentrated to dryness and processed as in above method.

\section{Single step Column Extraction and Cleanup} Method

Fortified soil (10 g) was taken in a beaker, mixed with 7-10 drops of ammonia and kept for 4-5 hours. When the smell of ammonia completely disappeared, $250 \mathrm{mg}$ of activated charcoal and 250 $\mathrm{mg}$ of florisil were added and mixed with glass rod. A properly cleaned glass column $(50 \times 2.0 \mathrm{~cm})$ was taken and plugged at the bottom with cotton plug. Anhydrous $\mathrm{Na}_{2} \mathrm{SO}_{4}$ was added to get approximately 2-inch layer and then soil mixture was added and tapped 4-5 times on rubber pad to get proper packing. Again cotton plug was placed on the top. 
The column was eluted with $100 \mathrm{~mL}$ acetone. Eluate was collected, solvent evaporated to dryness and residues dissolved in methanol for analysis.

\section{Accelerated Solvent Extraction (ASE)}

Accelerated solvent extraction was performed with an ASE 350 system (Dionex corporation, Sunnyvale, CA, USA). $10 \mathrm{~g}$ of sample was used in all extractions and the extract was collected in 250 $\mathrm{ml}$ of glass bottles with Teflon coated rubber caps. Extractions were performed at $80{ }^{\circ} \mathrm{C}$ temperature, extraction pressure was kept at 125 psi, static time $10 \mathrm{~min}$, flush-volume (60\%), actone was used as extraction solvent. The extract obtained was concentrated in vacuo using rotary evaporator. Afterwards, different extract solutions were prepared using methanol at a known concentration.

\section{Results and Discussion}

The studies were conducted to know the extraction efficiency and to establish the reliability and reproducibility of analytical methods. The soil samples were spiked at 0.1 and $0.2 \mu \mathrm{g} \mathrm{g}^{-1}$ for hexaconazole. Spiked samples were equilibrated for 24 hours. Various solvents were experimented (dichloromethane, hexane and acetone) and bestsuited solvent for extraction was adopted to get precisive and accurate results for hexaconazole residues. As compared to column and mechanical shaking, soxhlet extraction method was found to be the most effective in the conventional set of method of extracting hexaconazole residues from soil samples, it shows around $82 \%$ extraction efficiency. But this method was time consuming and required more solvent. As compared to soxhlet extraction, ASE gave the maximum recovery. The data of the recoveries of these extraction methods using acetone as an extracting solvent are presented in Figure 2 (a-d). Results shown that, recovery efficiency of hexaconazole was around $82 \%$ by using soxhlet technique while above $90 \%$ by using ASE in all experiments. Moreover, as compared with traditional soxhlet extraction, ASE required less the extraction time and lesser solvent. However, soxhlet method is generally, used for dry soil and mechanical shaking method is used for wet soil.

The ASE procedure is simple, requiring only mixing of the samples with drying agent and transferring the mixture to an extraction cell.
Fig no.2a Graphical representation of extraction efficiency of Alluvial soil

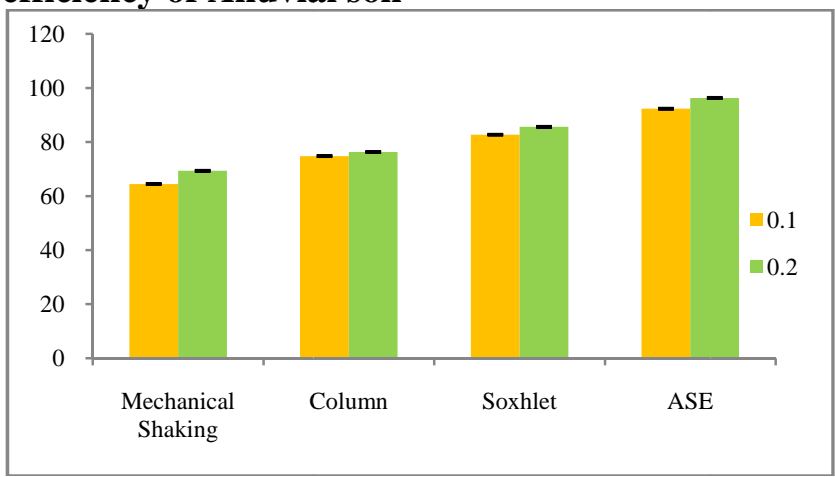

Fig no.2b Graphical representation of extraction efficiency of Red soil

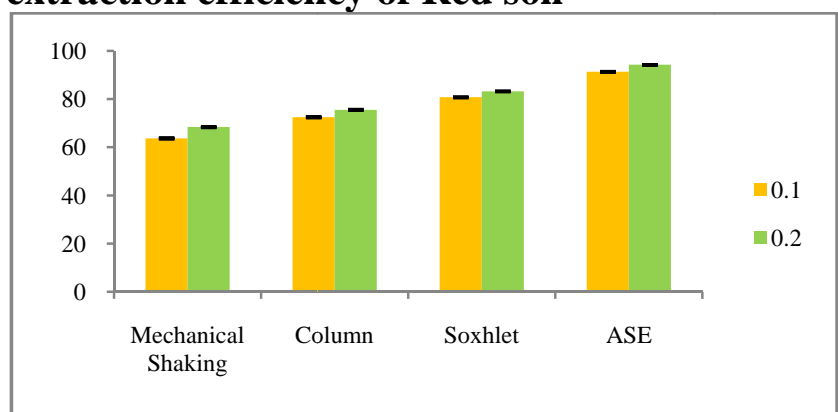

Fig no.2c Graphical representation of extraction efficiency of Laterite soil

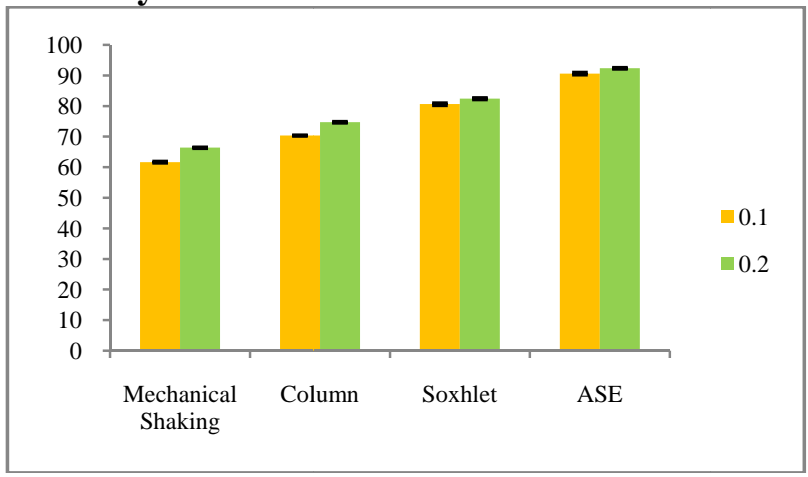

Fig no.2d Graphical representation of extraction efficiency of Black soil

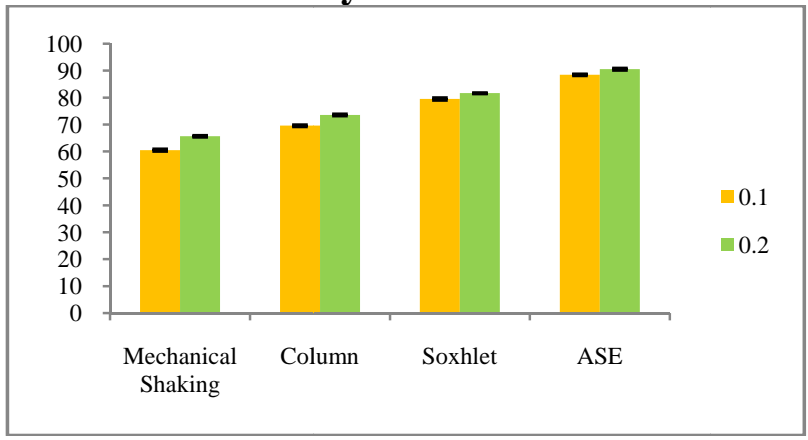


ASE used high temperature and high pressure triazole fungicides were stable under these conditions. This study demonstrated that ASE automatically and rapidly extracted hexaconazole from soils with good accuracy and precision. We have shown that organochlorine pesticides can be determined using ASE. The results found similar to earlier work reported by Okihashi et al. (1998).

\section{Conclusions}

Maximum extraction of pesticides is necessary for the analysis and determining their content in the moiety. Traditional solid-liquid extraction techniques are time consuming and require a large quantity of solvent. This not only increases operating costs but also causes various environmental hazards. Accelerated solvent extraction is advance extraction technique which is more precise, cost-effective, faster than the other coventional techniques and offering less solvent consumption, higher efficiency and reproducibility.

\section{References}

Hubert, A., Wenzel, K.D., Manz, M., Weissflog, L., Engewald, W., Schuumann, G., 2000. Anal. Chem. 72: 1294.

Santoro, A., Scopa, A., Bufo, S. A., Mansour, M., Mountacer, H., 2000. Photodegradation of the Triazole Fungicide Hexaconazole. Bull. Environ. Contam. Toxicol. 64:475-480.

Blanco, C., Pico, Y., Font, G., 2002b. Monitoring of five post harvest fungicides in fruit and vegetables by matrix solid-phase dispersion and liquid chromatography/mass spectrometry. $\boldsymbol{J}$. AOAC Int. 85 (3): 704-711.
Blanco, C., Pico, Y., Manes, J., Font, G., 2002a. Determination of fungicide residues in fruits and vegetables by liquid chromatography-atmospheric pressure chemical ionization mass spectrometry. J. Chromatogr. A 947 (2): 227-235.

Ekstrom, G., Hemming, H., Palmborg, M., 1996. Swedish pesticide risk reduction 1981-1995: food residues, health hazard, and reported poisonings. Rev. Environ. Contam. Toxicol. 147: 119147.

EL-Saeid, M.H., Shaht, M., 2000. Detection of pesticide residues and heavy metals in some fresh fruits and vegetables collected from Cairo. $1^{\text {st }}$ Mansoura Conf. of Food and Dairy Technol. 17-19 October, Cairo, Egypt, pp. 183-203.

FDA, 1993. Monitoring program. J. AOAC Int. 76 (5): 127A-148A. Singh, N. and Dureja, P., 2000. Persistence of hexaconazole, a triazole fungicide in soils. J. Environ. Sci. Health B. 35(5): 549-558.

Neidert, E., Saschenbrecker, P.W., 1996. Occurrence of pesticide residues in selected agricultural food commodities available in Canada. J. AOAC Int. 79 (2): 549-566.

Okihashi, Masahiro, Kitagawa, Yoko, Akutsu, Kazuhiko, Obana, Hirotaka, Tanaka, Yukio, 2005. Rapid method for the determination of 108 pesticide residues in foods by gas chromatography/mass spectrometry and fame photometric detection. J. Pestic. Sci. 30 (4): 368-377.

Ripley, B.D., Ritcey, G.M., Harris, C.R., Denomme, M.A., Lissemore, L.I., 2003. Comparative persistence of pesticides on selected cultivars of specialty vegetables. J. Agric. Food Chem. 51 (5): 1328-1335.

Roy, R.R., Albert, R.H., Wilson, P., Laski, R.R., Roberts, J.I., Hoffmann, T.J., Bong, R.L., Bohannon, B.O., Yess, N.J., 1995. U.S. Food and Drug Administration pesticide program: incidence/ level monitoring of domestic and imported pears and tomatoes. J. AOAC Int. 78 (4): 930-940.

Valenzuela, A.I., Redondo, M.J., Pico, Y., Font, G., 2000. Determination of abamectin in citrus fruits by liquid chromatography-electrospray ionization mass spectrometry. $\boldsymbol{J}$. Chromatogr. A. 871(1-2): 57-65.

Worthington, P.A. 1991. Synthesis of 1,2,4-triazole compounds related to the fungicides flutriafol and hexaconazole. Pestic Sci. 31: 457498. 